Çukurova Üniversitesi Mühendislik Mimarlık Fakültesi Dergisi, 33(3), ss. 81-92, Eylül 2018

Çukurova University Journal of the Faculty of Engineering and Architecture, 33(3), pp. 81-92, September 2018

\title{
Beton Ağırlık Barajların Sismik Performanslarına Seçilen Kesit Geometrisinin Etkisi
}

\author{
Alper ALDEMIR* ${ }^{*}$ \\ ${ }^{1}$ Hacettepe Üniversitesi, Mühendislik Fakültesi, İnşaat Mühendisliği Bölümü, Ankara
}

Geliş tarihi: $12.02 .2018 \quad$ Kabul tarihi: 15.10 .2018

$\ddot{\mathbf{O} z}$

$\mathrm{Bu}$ çalışmada, kesit geometrilerinin beton ağırlık barajların sismik performanslarına etkisi incelenmiştir. $\mathrm{Bu}$ amaçla, beton ağıllık barajların tasarımı aşamasında kullanılagelen altı farklı kesit geometrisi seçilmiş ve oluşturulan numerik modeller üç farklı yüksekliğe sahip Gündüzler, Naras ve Andıraz barajlarına uyarlanmıştır. Böylece tasarım aşamasında kullanılan değişkenleri değiştirmeksizin, kesit geometrilerinin barajların sismik taleplerine etkisi incelenmiştir. Seçilen kesitlerin tamamında eşit miktarda malzeme kullanılmıştır. Böylelikle hangi kesit tipinin malzemeyi en optimum şekilde kullanmaya izin verdiği araştııılmıştır. Numerik modellerde rezervuar etkileşimi için akustik akışkan elemanlar kullanılmıştır. Modeller üç adet deprem senaryosuna tabi tutulmuştur. Yapılan analiz sonuçlarına göre Kesit K3'ün en elverişli sonuçları ürettiği gözlemlenmiştir.

Anahtar Kelimeler: Kesit geometrisi, Sismik performans, Ağırlık barajlar

\section{Effect of Selected Cross-section Geometry on the Seismic Performance of Concrete Gravity Dams}

\begin{abstract}
In this study, the effect of section geometry on the seismic performance of concrete gravity dams was investigated. For this purpose, six different cross-sectional geometries widely-used at the design phase of concrete gravity dams were selected and the numerical models were adapted to the Gunduzler, Naras and Andiraz dams. Thus, the effect of section geometry on the seismic demands have been examined without changing the variables used during the actual design. Equal amounts of material were used in all of the selected sections. So, it was investigated which section type allowed the most optimal use of the material. Acoustic fluid elements were utilized for simulating the interaction between the reservoir and the dam body. The numerical models were analyzed under the effect of three different earthquake scenarios. According to the analysis results, it was observed that Section K3 produced the most favorable results.
\end{abstract}

Keywords: Section geometry, Seismic performance, Gravity dams

*Sorumlu Yazar (Corresponding Author): Alper Aldemir, alperaldemir@hacettepe.edu.tr 


\section{GíRiş}

Ülkemizin enerji ihtiyacını karşılamak üzere 2000'li yılların başından itibaren hidroelektrik santral ve baraj inşașında büyük bir artış gözlemlenmiştir. Bunun temel sebepleri olarak, ülkemizin teknolojik olarak ilerleme çalışmalarındaki ivme ve ülkemizin artan nüfusu gösterilebilir. Ayrıca, ülkemiz bulunduğu coğrafi konum itibariyle birçok zengin su kaynağ bulundurduğundan ötürü de hidroelektrik santraller ülkemizin enerji üretim politikasında önemli bir noktada bulunmaktadır. Barajlar aynı zamanda tarım ülkesi olmamız nedeniyle hem elektrik hem de sulama ihtiyacımızı karşılaşmaya yardımcı olmaktadır.

Ülkemiz baraj stokunun önemli bir kısmını dolgu ağırlık barajlar oluşturmaktadır. Fakat, son yıllarda beton ağırlık, silindirle sıkıştırılmış beton (SSB) ağırlık ve ön yüzü beton kaplı kaya dolgu ağırlık barajlar (ÖYBKKD) büyük bir ivme yakalamıştır [1]. Yeni yapım teknikleri ve artan teknolojiyle birlikte baraj inşasında kullanılan malzeme tiplerinde böyle bir değişim gözlemlenmiştir. Bir başka değişle, teknolojik gelişmelerle birlikte beton, SSB ve ÖYBKKD baraj tiplerinin inşa süreleri oldukça kısalmıştır. Ayrıca, bahsi geçen bu malzemeler dolgu barajlarda kullanilan malzemelerden çok daha iyi bir dayanım ve dayanıklılığa sahiptir.

Bilindiği üzere, maalesef su kaynaklarının bulunduğu yörelerin birçoğu deprem tehdidi altındadır. Ne yazık ki; deprem etkileri altında barajların davranışı deprem mühendisliği dalındaki en karmaşık problemlerden birisidir. Bunun en önemli sebepleri arasında, barajların oturdukları temellere oranla daha rijit olmaları sebebiyle yapı zemin etkileşiminin dikkate alınma zorunluluğu, deprem esnasında rezervuardaki suyun barajla etkileşiminin bulunması vs. gösterilebilir. Tasarım aşamasında gerekli taleplerin daha doğru ve gerçeğe yakın bir şekilde elde edilebilmesi için literatürde birçok modelleme çalışmaları bulunmaktadir $[2,3]$.

Barajlardaki talepleri en çok etkileyen etmenlerden rezervuar etkileşiminin numerik modellenmesi metotları baraj tasarımında ilk ele alınan konulardandır. 1933 yılında Westergaard [4] tarafından beton ağırlık barajlar üzerine etki eden hidrodinamik yükleri tahmin eden çalışma, baraj mühendisliği için deprem etkilerinin göz önünde bulundurulması konusunda öncü bir öneme sahiptir. Sadece memba yüzü dik olan barajlar için önerilen bu yöntem daha sonra Kuo [5] tarafindan "kütle ekleme" metodu ile eğimli yüze sahip barajlara da genellenmiştir. Chopra [6] tarafından geliştirilen ve sonra Fenves ve diğer araştırmacıların da katılımıyla nihayete erdirilen yöntemler [7-11] sonlu eleman yöntemleri kullanarak, frekans tanım alanında kesin çözüm yapma imkânı sunmuştur. Bu çalışmalara ek olarak Fenves ve Chopra [12-14] bir dizi çalışma ile baraj deprem performansının tek serbestlik dereceli bir sistem ile de tahmin edilebileceğini gözler önüne sermiştir. $\mathrm{Bu}$ yöntemlerin kullanıldığ 1 çalışmalar daha sonra pek çok araştırmacı tarafından yakın geçmişte dahi kullanılmıştır [15-17]. Bu modelleme teknikleri daha sonra barajların tasarımı aşamasında uyulması gereken kriterlerin bir tasarım şartnamesi olarak oluşturulmasına ön ayak olmuştur [18,19]. Fakat, tasarımı oldukça karmaşık modelleme teknikleri gerektiren barajların birçok farklı kesit geometrisi seçilerek tasarlanma imkânı bulunmaktadır ve hiçbir tasarım şartnamesinde kesit geometrisinin tasarımı ne ölçüde etkileyeceğine dair yol gösterici bir ibare bulunmamaktadır. Bu da tasarımcıları daha önce aşina oldukları kesitleri kullanmaya itmektedir.

$\mathrm{Bu}$ çalışmada, kullanılan kesit geometrilerinin barajların sismik performanslarına etkisi incelenmiştir. Bu amaçla farklı yüksekliklere sahip üç adet baraj (Gündüzler Baraj1, $\mathrm{H}=65 \mathrm{~m}$; Naras Baraj1, $\mathrm{H}=78 \mathrm{~m}$ ve Andıraz Baraj1, $\mathrm{H}=142 \mathrm{~m}$ ) seçilmiştir. Seçilen bu barajlar, tasarım kesitleri de dâhil olmak üzere toplam altı farklı kesit kullanılarak modellenmiştir. Kesit seçiminde dikkat edilen husus her kesitte eşit miktarda malzeme kullanılmasıdır. Böylece hangi kesit tipinin malzemeyi en optimum şekilde kullanmaya izin verdiği araştırılmıştır. Barajlar dolu rezervuar koşullarını yansıtabilmek üzere akustik elemanlar kullanılarak modellenmiştir. Seçilen barajların modelleriyle, barajların tasarım aşamalarında kullanılan sahaya özel hazırlanan üçer adet sentetik 
yer hareketi etkisi altında zaman tanım alanında analizler gerçekleştirilmiştir.

\section{SEÇILLEN BARAJLAR}

$\mathrm{Bu}$ çalı̧̧ma kapsamında numerik analizleri gerçekleştirilecek olan barajlar Gündüzler, Naras ve Andıraz Barajı'dır. Bu barajların bu çalışmada kullanılmalarının temel sebebi, kesit seçiminin farklı baraj yüksekliğine sahip barajlar üzerindeki etkilerini de inceleyebilmektir. Böylece hem orta yüksekliğe sahip hem de yüksek baraj davranışları incelenebilecektir. Seçilen barajların tasarım kesitleri Şekil 1'de özetlenmektedir.

Bahsi geçen barajlar eşit miktarda malzeme kullanılarak altı farklı kesit için tekrar modellenmiştir. $\mathrm{Bu}$ aşamada seçilen farklı kesit geometrileri Şekil 2'de verilmektedir. Her baraj kesiti için tasarım kesitiyle eşit miktarda malzeme kullanmak için gerekli parametreler ise Çizelge 1-3'de özetlenmektedir. (a)

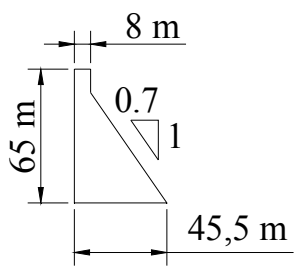

(b)

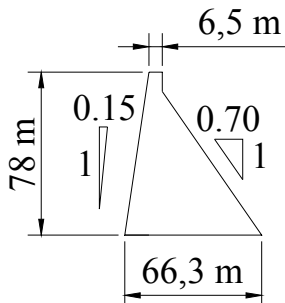

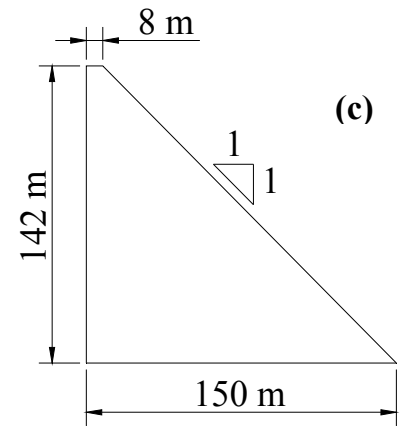

Şekil 1. (a) Gündüzler, (b) Naras ve (c) Andıraz Barajlarının tasarım kesitleri

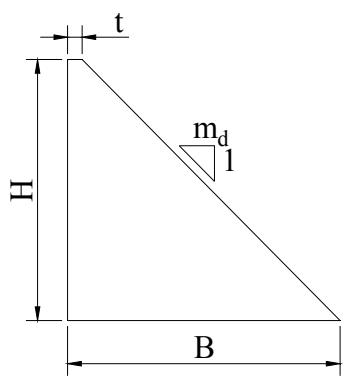

Kesit 1

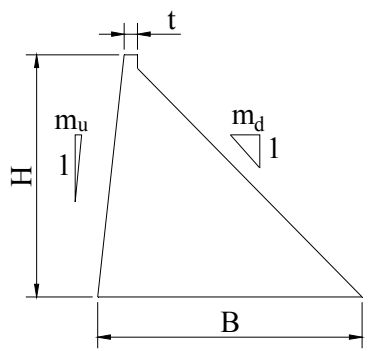

Kesit 4

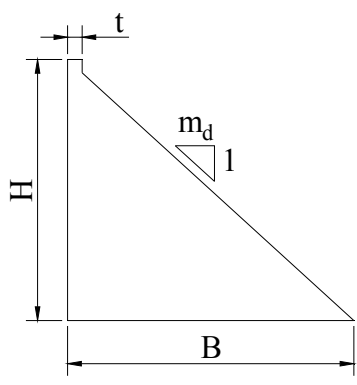

Kesit 2

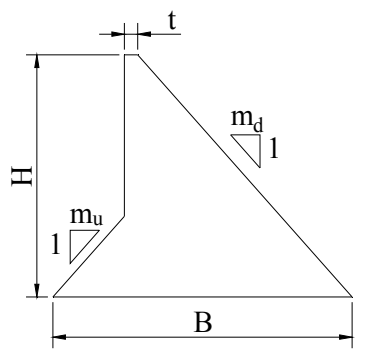

Kesit 5

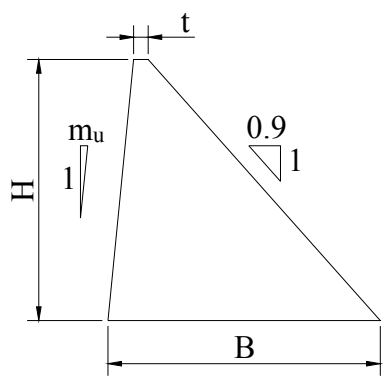

Kesit 3

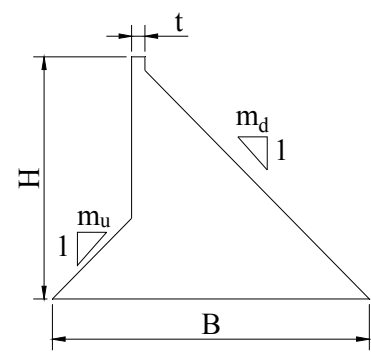

Kesit 6

Şekil 2. Kullanılan farklı kesit tipleri 
Çizelge 1. Gündüzler Barajı için kesit parametreleri *Tasarım kesiti

\begin{tabular}{|c|c|c|c|c|c|c|}
\hline Kesit & H (m) & B (m) & $t(\mathrm{~m})$ & $\mathbf{m}_{\mathbf{u}}$ & $\mathbf{m}_{\mathbf{d}}$ & $\operatorname{Alan}\left(\mathrm{m}^{2}\right)$ \\
\hline 1 & 65 & 38,9 & 8 & 0 & 0,475 & 1523 \\
\hline $2^{*}$ & 65 & 45,5 & 8 & 0 & 0,700 & 1524 \\
\hline 3 & 65 & 38,9 & 8 & 0,048 & 0,428 & 1523 \\
\hline 4 & 65 & 45,5 & 8 & 0,070 & 0,630 & 1529 \\
\hline 5 & 65 & 45,1 & 8 & 0,428 & 0,428 & 1524 \\
\hline 6 & 65 & 46,4 & 8 & 0,628 & 0,628 & 1525 \\
\hline
\end{tabular}

Çizelge 2. Naras Baraj1 için kesit parametreleri *Tasarım kesiti

\begin{tabular}{|c|c|c|c|c|c|c|}
\hline Kesit & H (m) & B (m) & $t(m)$ & $\mathbf{m}_{\mathbf{u}}$ & $\mathbf{m}_{\mathbf{d}}$ & $\operatorname{Alan}\left(m^{2}\right)$ \\
\hline 1 & 78 & 60,6 & 6,5 & 0 & 0,674 & 2615 \\
\hline 2 & 78 & 66,5 & 6,5 & 0 & 0,852 & 2616 \\
\hline 3 & 78 & 60,6 & 6,5 & 0,067 & 0,607 & 2615 \\
\hline $4^{*}$ & 78 & 66,3 & 6,5 & 0,150 & 0,700 & 2615 \\
\hline 5 & 78 & 71,5 & 6,5 & 0,625 & 0,625 & 2619 \\
\hline 6 & 78 & 73,2 & 6,5 & 0,766 & 0,766 & 2616 \\
\hline
\end{tabular}

Çizelge 3. Andıraz Barajı için kesit parametreleri *Tasarım kesiti

\begin{tabular}{|c|c|c|c|c|c|c|}
\hline Kesit & H (m) & B (m) & $t(m)$ & $\mathbf{m}_{\mathbf{u}}$ & $\mathbf{m}_{\mathbf{d}}$ & $\operatorname{Alan}\left(\mathrm{m}^{2}\right)$ \\
\hline $1^{*}$ & 142 & 150 & 8 & 0 & 1,000 & 11218 \\
\hline 2 & 142 & 157,6 & 8 & 0 & 1,111 & 11219 \\
\hline 3 & 142 & 150 & 8 & 0,100 & 0,900 & 11218 \\
\hline 4 & 142 & 157,6 & 8 & 0,111 & 0,999 & 11223 \\
\hline 5 & 142 & 178,4 & 8 & 0,900 & 0,900 & 11218 \\
\hline 6 & 142 & 188,9 & 8 & 0,998 & 0,998 & 11212 \\
\hline
\end{tabular}

\subsection{Yer Hareketleri}

Çalışma kapsamında barajların sismik performansları zaman tanım alanında analizler vasitasıyla belirleneceğinden yer hareketlerine ihtiyaç duyulmaktadır. Bu çalışmada, seçilen barajların, tasarımları aşamasında kullanılan karakteristik deprem senaryolarından (MCE: Maximum Characteristic Earthquake) faydalanılacaktır. Her baraj tipi için üçer adet yer hareketi kullanılacaktır. $\mathrm{Bu}$ yer hareketleri Şekil 3-5'de özetlenmektedir.

\subsection{Numerik Model Detayları}

Bu çalışma kapsamında seçilen baraj kesitlerinin iki boyutlu numerik modelleri oluşturulmuştur. Analizler için çok amaçlı sonlu eleman programı ANSYS [20] kullanılmıştır. Modellerde baraj gövdesi ve zemin 4-düğüm noktalı eşparametrik dörtgen elemanlarıyla (PLANE42), rezervuardaki $\mathrm{su}$ ise akustik akışkan elemanlar (FLUID29) kullanılarak modellenmiştir.

Modellerde Gauron ve arkadaşları [21] tarafından da sismik özellikleri tahmin etmedeki başarısı 
doğrulanan akustik akışkan elemanlara sahip kütlesiz zemin modelleri kullanılmıştır. Bu modelleme tekniğinin barajların zorlanmış titreşim testi sonuçlarıyla elde edilen hâkim modlarına ait frekansları $\% 5$ 'ten daha düşük bir hata oranıyla tahmin edebildiği gösterilmiştir [21].

USACE [18] ve Sevim ve arkadaşları [22] tarafından önerildiği gibi, zemin malzemesi baraj gövdesinden baraj yüksekliğinin üç katı kadar derinlik ve genişliğe kadar uzatılmıştır. Akustik akışkan elemanlar içeren numerik modellerde serbestlik dereceleri arasındaki uyumsuzluğu gidermek için yapısal elemanlara bağlı akışkan elemanlarda basınç ve deplasman serbestlik dereceleri kullanılırken diğer akışkan elemanlarda sadece basınç serbestlik derecesi kullanılmıştır. Bu durum simetrik olmayan kütle ve rijitlik matrislerine sebep olmaktadır (Eşitlik 1). Ayrıca rezervuardaki geri yansımaları engellemek için rezervuarın sonundaki akışkan elemanlar için içsel sürtünme değeri maksimum olarak alınmıştır.

Bu çalışma kapsamında kullanılan numerik model Şekil 6'da özetlenmektedir. Şekil 6'da belirtildiği gibi numerik modelde stabilite sağlamak için mesnetler tanımlanmıştır. Bunun için rezervuarın en üst kotundaki tüm düğüm noktalarında basınç serbestlik derecesi sıfır olarak alınmıştır. Bu varsayım rezervuardaki basınç dağılımını doğru yansıtmak için önem arz etmektedir. Ayrıca, zeminin tüm sınır koşulları kayar mesnet olarak tanımlanmıştır. Bir başka deyişle zeminin en dışında bulunan düğüm noktalarının bulundukları yüzeye dik yönde hareket etmeleri engellenmiştir [19].
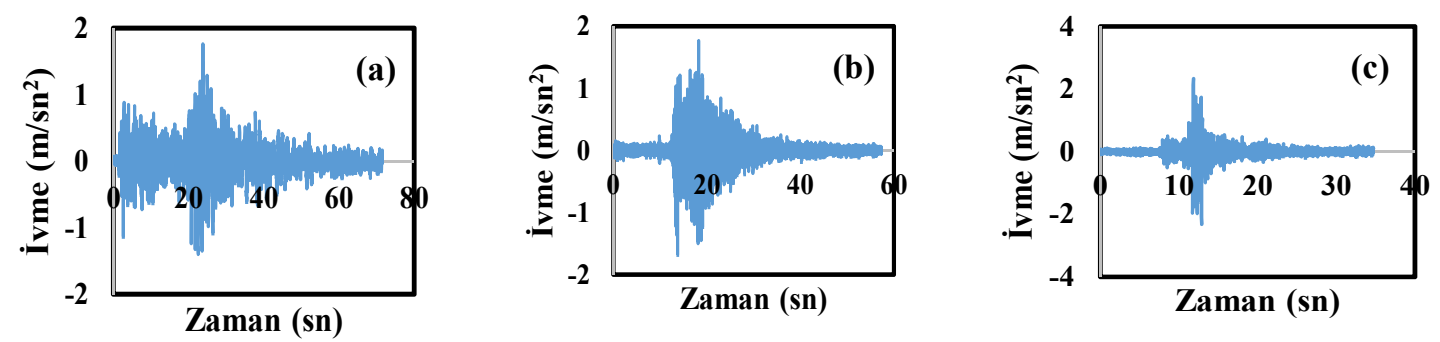

Şekil 3. Gündüzler Baraj1 yer hareketleri: (a) MCE1, (b) MCE2 ve (c) MCE3
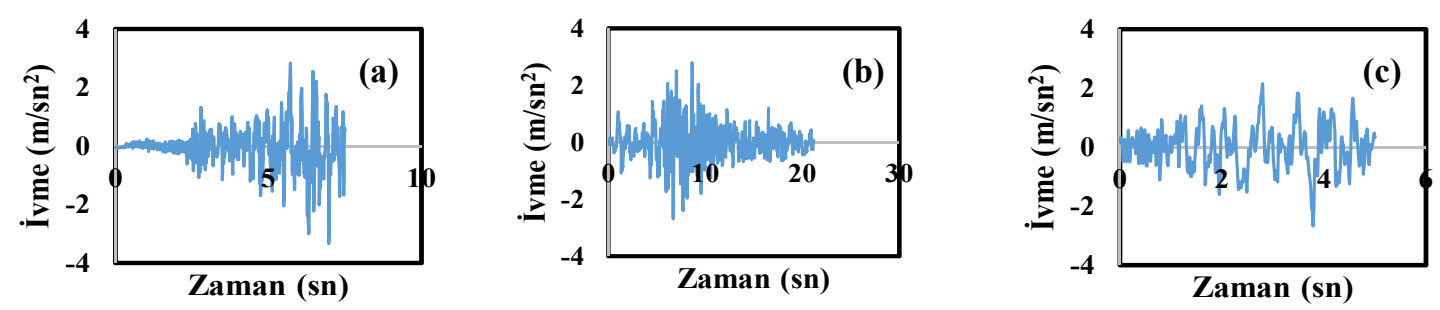

Şekil 4. Naras Baraj1 yer hareketleri: (a) MCE1, (b) MCE2 ve (c) MCE3
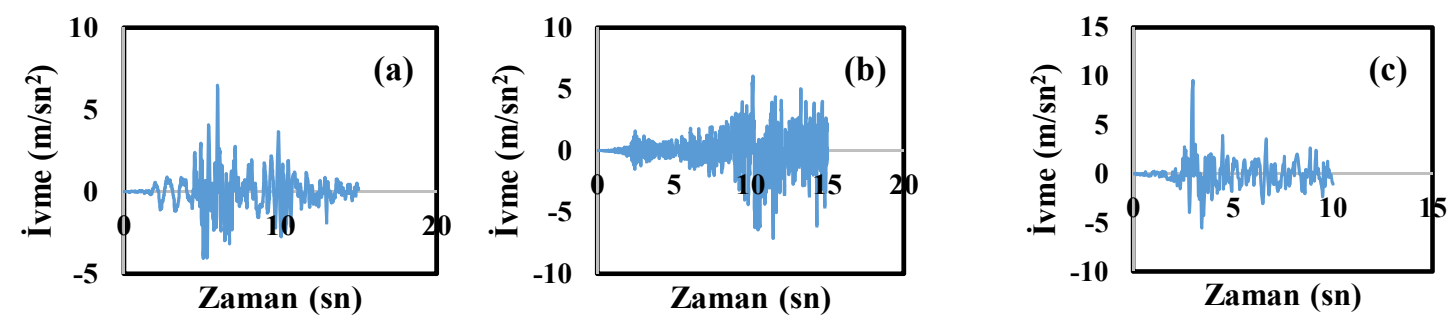

Şekil 5. Andıraz Barajı yer hareketleri: (a) MCE1, (b) MCE2 ve (c) MCE3 


$$
\begin{aligned}
& {\left[\mathrm{M}_{\mathrm{s}}\right]\{\ddot{\mathrm{u}}\}+\left[\mathrm{C}_{\mathrm{s}}\right]\{\dot{\mathrm{u}}\}+\left[\mathrm{K}_{\mathrm{s}}\right]\{\mathrm{u}\}=\left\{\mathrm{F}_{\mathrm{s}}\right\}+[\mathrm{R}]\{\mathrm{p}\}} \\
& {\left[\mathrm{M}_{\mathrm{f}}\right]\{\ddot{\mathrm{p}}\}+\left[\mathrm{C}_{\mathrm{f}}\right]\{\dot{\mathrm{p}}\}+\left[\mathrm{K}_{\mathrm{f}}\right]\{\mathrm{p}\}=\left\{\mathrm{F}_{\mathrm{f}}\right\}-\rho_{\mathrm{w}}[\mathrm{R}]^{\mathrm{T}}\{\ddot{\mathrm{u}}\}} \\
& \left.\left[\begin{array}{cc}
\mathrm{M}_{\mathrm{s}} & 0 \\
\rho_{\mathrm{w}}[\mathrm{R}]^{\mathrm{T}} & \mathrm{M}_{\mathrm{f}}
\end{array}\right]\left\{\begin{array}{l}
\ddot{u} \\
\ddot{\mathrm{p}}
\end{array}\right\}+\left[\begin{array}{cc}
\mathrm{C}_{\mathrm{s}} & 0 \\
0 & \mathrm{C}_{\mathrm{f}}
\end{array}\right] \begin{array}{c}
\dot{\mathrm{u}} \\
\dot{\mathrm{p}}
\end{array}\right\}+\left[\begin{array}{cc}
\mathrm{K}_{\mathrm{s}} & -\mathrm{R} \\
0 & \mathrm{~K}_{\mathrm{f}}
\end{array}\right]\left\{\begin{array}{l}
\mathrm{u} \\
\mathrm{p}
\end{array}\right\}=\left\{\begin{array}{l}
\mathrm{F}_{\mathrm{s}} \\
\mathrm{F}_{\mathrm{f}}
\end{array}\right\}
\end{aligned}
$$

* M kütle matrisi, C sönüm matrisi, K rijitlik matrisi, F kuvvet matrisi, ü ivme vektörü, $\dot{u}$ hız vektörü, u deplasman vektörü, p basınç vektörü, $\dot{p}$ basıncın zamana göre değişimi vektörü, $\ddot{p} \dot{p}$ ’ın zamana göre değişim vektörü, $\mathrm{R}$ akışkan ve yapının etkileşimde olduğu düğüm noktalarını belirten matris ve $\rho_{w}$ suyun özkütlesini ifade etmektedir. S alt indisi yapı elemanlarını ve f indisi ise akışkan elemanlarını ifade etmek için kullanılmıştır.

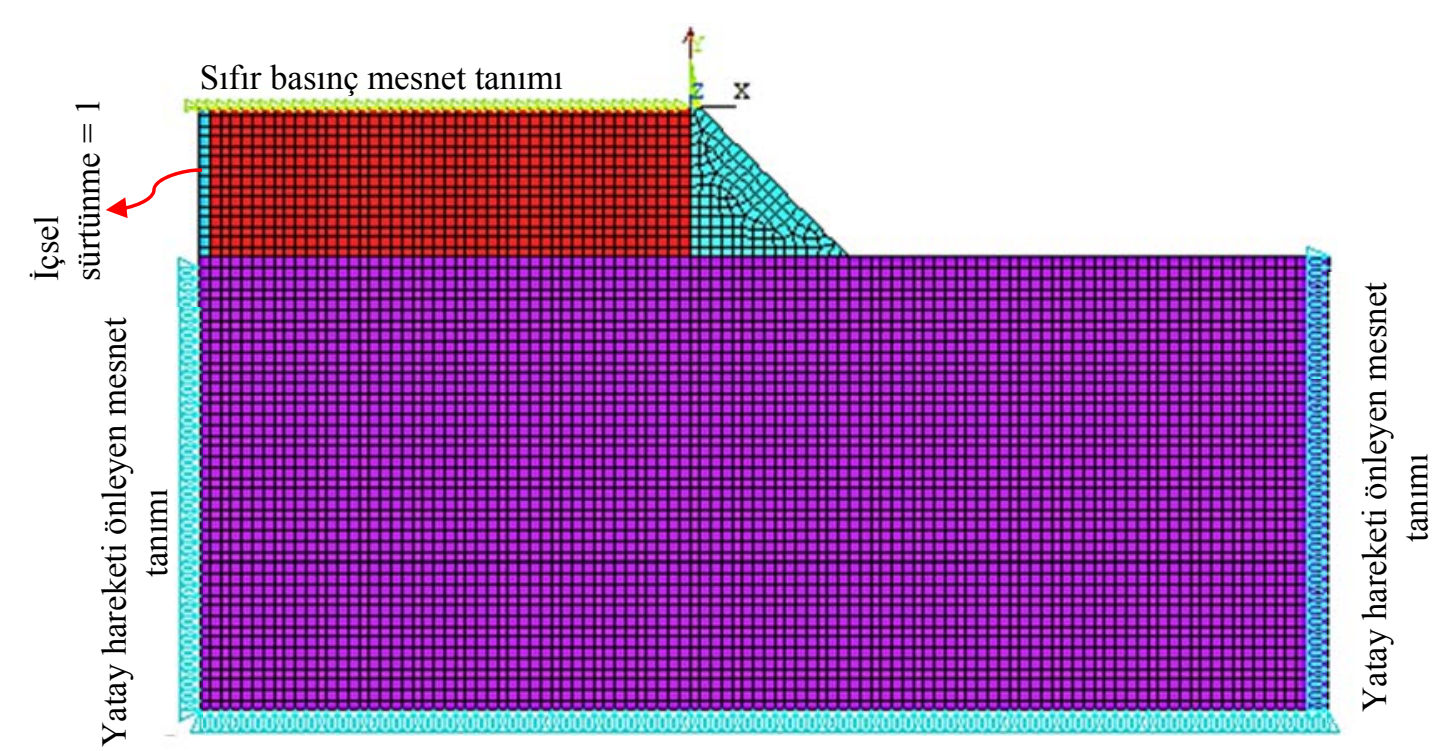

Düşey hareketi önleyen mesnet tanımı

Şekil 6. Numerik model detayları

Numerik modellerin hepsinde Rayleigh sönümleme matrisi kullanılmıştır. Tüm modellerde Rayleigh katsayıları ilk ve etkin kütle katsayısı \%90 olan modda \%5'lik sönüm oranı oluşturacak şekilde seçilmiştir.

\section{NUMERIKK ANALIZLER}

Bu çalışma kapsamında farklı yüksekliklere ve kesit tiplerine sahip numerik modeller oluşturulmuştur. Kesitler oluşturulurken dikkat edilen en önemli nokta, tüm kesitlerde eşit miktarda malzeme kullanılmasıdır $\quad(\% 0,5$ hata payıyla $)$ Tüm modellerde kullanılan barajların zemin sondajlarından elde edilen zemin elastisite modülleri ve tasarım aşamasında önerilen beton elastisite modülleri (E) kullanılmıştır. Ayrıca, Çizelge 4'te $\rho$ "öz kütleyi” ve c ise "sudaki sonik dalga hızını" sembolize etmektedir. Bahsi geçen parametrelerin değerleri Çizelge 4'te özetlenmektedir.

Numerik modelleri oluşturulan 18 farklı baraj modeli için üçer adet zaman tanım alnında analizler gerçekleştirilmiştir. Tüm modeller, ilk olarak düşey yük etkileri altında analiz edilmiştir. Daha sonra ise 
yer hareketi barajın aksına dik yönde etkitilmiştir. Daha sonra baraj kretinde oluşan deplasman ve ivme talepleri not edilmiştir. Ayrıca, baraj gövdesinde oluşan maksimum asal gerilmelerin zamana bağlı değişimleri de elde edilmiştir. $\mathrm{Bu}$ analizler sonucunda seçilen kesit geometrisinin barajın performansına bir etkisi olup olmadığı irdelenmiştir. Ayrıca, her bir kesit tahkiki farklı yüksekliklere sahip baraj geometrileri için de gerçekleştirildiği için gözlemlenen davranışa baraj yüksekliğinin etkisi de incelenmiştir. Son olarak benzer yüksekliğe sahip iki baraj kesitinin (Gündüzler ve Naras) farklı zemin rijitiliği durumları için (Gündüzler ve Naras barajları için zeminin elastisite modülleri sirasıyla $16000 \mathrm{MPa}$ ve 7000MPa'dır.) karşılaştırması da yapılmıştır.

\section{SONUÇLARIN TARTIŞMASI}

Gerçekleştirilen analizler sonucunda numerik modellerde elde edilen maksimum kret deplasmanları, kret ivmeleri ve baraj gövdesindeki azami asal gerilme değerleri Şekil 7-9'da özetlenmektedir. Şekil 7-9'dan kolaylıkla anlaşılacağ1 üzere seçilen kesit geometrisi deplasman, ivme ve gerilme taleplerini etkilemektedir (Çizelge 5-7). Analiz sonuçları incelenirken hem üç MCE analizinin ortalama değerleri hem de MCE senaryolarından elde edilen maksimum talepler göz önünde bulundurulmuştur. Bunun temel sebebi kullanılan deprem senaryosu adedi üç olduğu için tasarım şartnamesi (UBK [19]) gereği tasarımda bu kullanılan deprem senaryolarından azami talep oluşturanın dikkate alınması gerekliliğidir. Fakat, ortalama değerler ise genel olarak kesitin ortalama performansının değerlendirilmesi için önem arz etmektedir. Çünkü, ortalama talep istemleri bir adet deprem senaryosundan kaynaklı artışların etkisini azaltmaktadir.
Sonuçlar incelendiğinde, Gündüzler barajı için ortalama kret deplasmanı, kret ivmesi ve azami asal gerilme değeri açısından en olumlu sonuç 3 numaralı kesit (K3) seçildiğinde elde edilmektedir (Şekil 5). MCE senaryolarının maksimum talepleri göz önünde bulundurulduğunda da aynı gözlemin geçerli olduğu tespit edilmektedir (Çizelge 5). Zemini Gündüzler barajına oranla daha az rijitliğe sahip Naras barajına ait sonuçlar incelendiğinde ise, ortalama kret deplasmanı, kret ivmesi ve azami asal gerilme değeri açısından en olumlu sonuç 1 numaralı kesit (K1) seçildiğinde elde edilmektedir (Şekil 6). MCE senaryolarının maksimum talepleri göz önünde bulundurulduğunda da aynı gözlemin geçerli olduğu tespit edilmektedir (Çizelge 6). Bu sonuçlar 1şığı altında aslında zemin rijitliğinin de kesit seçiminde etkili olduğu gözlemlenmiştir. Son baraj tipi olan Andıraz barajı sonuçlarına bakıldığında ise, Gündüzler barajı gibi ortalama kret deplasmanı ve kret ivmesi değeri açısından en olumlu sonuç 3 numaralı kesit (K3) seçildiğinde elde edilmektedir (Şekil 7). Ayrıca, asal gerilmeler için en iyi performans 6 numaralı kesit (K6) seçildiğinde elde edilmektedir. Fakat, K3 kesitinin performansı da K6 kesitine oldukça yakın durumdadır. Bu yüzden bu yükseklik için de K3 kesitinin en elverişli sonuçları verdiği söylenebilir.

Genel olarak K1 ve K3 kesitlerinin talepleri daha azalttığı gözlemlenmektedir. $\mathrm{Bu}$ nedenle kesit seçimlerinde sistem noktasının kullanılması yerine barajın mansap eğiminin direk kret yüksekliğine bağlanmasıyla elde edilen kesitlerin malzemenin daha efektif kullanılmasina yol açtığı gözlemlenmiştir (K1, K3 ve K6 gibi). Ayrıca, bu çalışma kapsamında gerçekleştirilen parametrik çalışma kapsamında barajın ön yüzüne eğim verilmesi de tavsiye edilmektedir.

Çizelge 4. Modellerde kullanılan malzeme özellikleri

\begin{tabular}{|c|c|c|c|c|c|c|}
\hline Baraj Adı & $\begin{array}{c}E_{\text {baraj }} \\
(\mathrm{MPa})\end{array}$ & $\rho_{\text {baraj }}\left(\mathrm{kg} / \mathrm{m}^{3}\right)$ & $\begin{array}{c}\mathrm{E}_{\text {zemin }} \\
(\mathrm{MPa})\end{array}$ & $\rho_{\text {zemin }}\left(\mathrm{kg} / \mathrm{m}^{3}\right)$ & $\mathrm{c}(\mathrm{m} / \mathrm{sn})$ & $\rho_{\text {su }}\left(\mathrm{kg} / \mathrm{m}^{3}\right)$ \\
\hline Gündüzler & 21250 & 2400 & 16000 & 10 & 1460 & 1000 \\
\hline Naras & 21250 & 2400 & 7000 & 10 & 1460 & 1000 \\
\hline Andıraz & 23750 & 2400 & 10800 & 10 & 1460 & 1000 \\
\hline
\end{tabular}




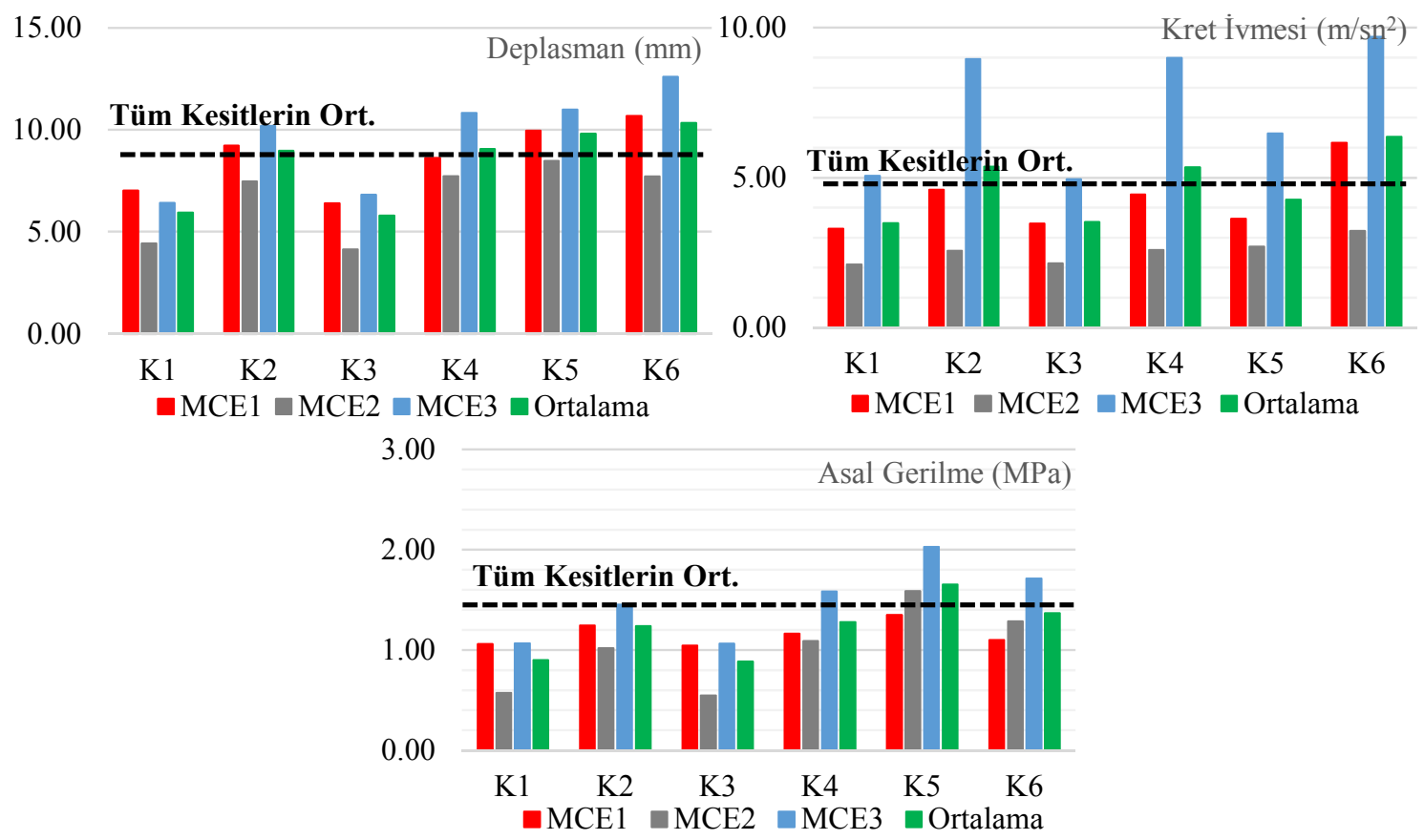

Şekil 7. Farklı kesitler için gündüzler barajı analiz sonuçları

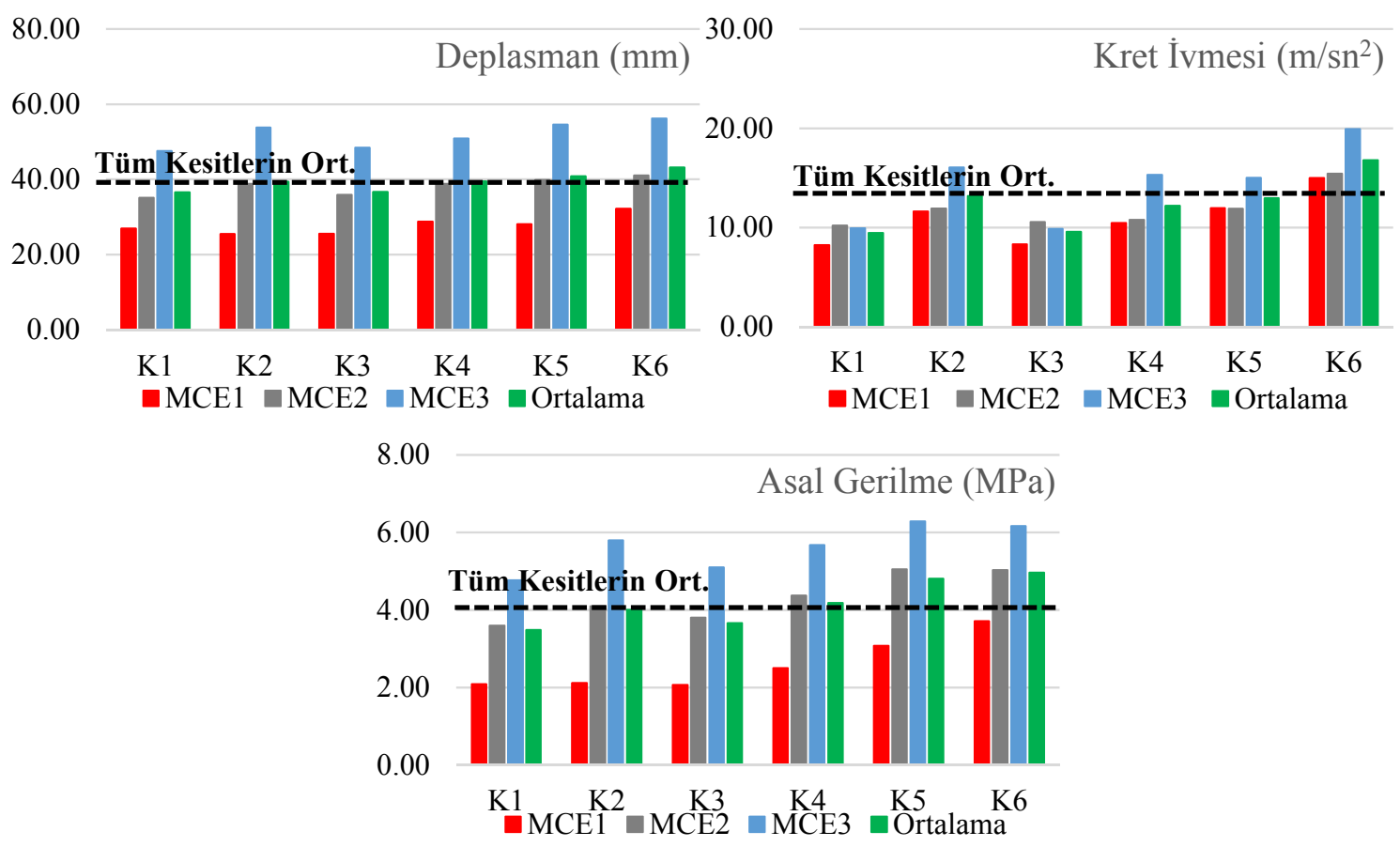

Şekil 8. Farklı kesitler için naras barajı analiz sonuçları 
100.00

Deplasman (mm)

80.00

60.00

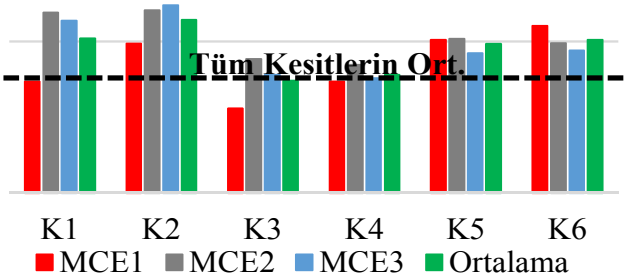

30.00

20.00

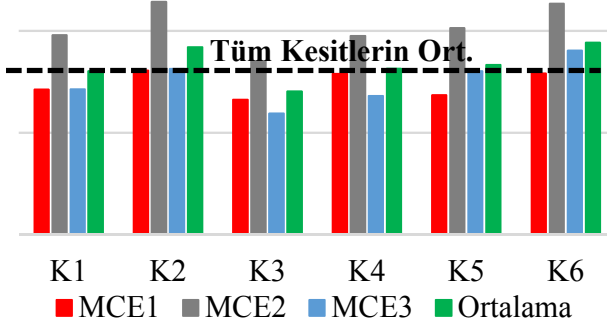

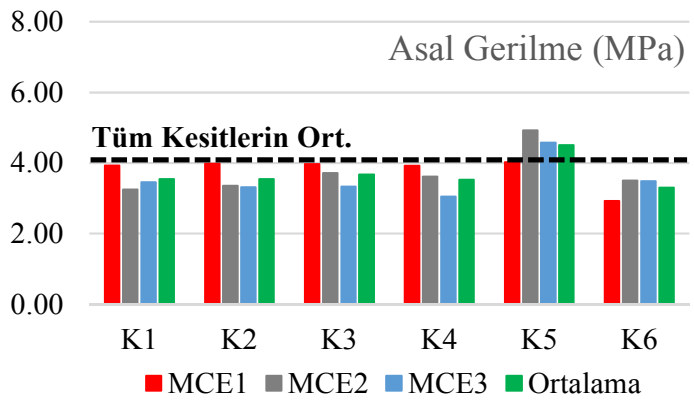

Şekil 9. Farklı kesitler için Andıraz Barajı analiz sonuçları

Çizelge 5. Gündüzler Barajı numerik modellerinin analiz sonuçları

\begin{tabular}{|c|c|c|c|c|c|c|c|c|c|c|c|c|}
\hline \multicolumn{9}{|c|}{ Maksimum Kret Deplasman1 (mm) } & \multicolumn{3}{c|}{ Maksimum Kret Ivmesi $\left(\mathrm{m} / \mathrm{sn}^{2}\right)$} & \multicolumn{4}{c|}{ Azami Asal Gerilme (MPa) } \\
\hline Kesit & MCE1 & MCE2 & MCE3 & Mak, & MCE1 & MCE2 & MCE3 & Mak, & MCE1 & MCE2 & MCE3 & Mak, \\
\hline 1 & 7,01 & 4,42 & 6,41 & 7,01 & 3,29 & 2,10 & 5,05 & 5,05 & 1,06 & 0,57 & 1,07 & 1,07 \\
\hline 2 & 9,23 & 7,48 & 10,18 & 10,18 & 4,59 & 2,56 & 8,95 & 8,95 & 1,25 & 1,02 & 1,45 & 1,45 \\
\hline 3 & 6,40 & 4,14 & 6,81 & $\mathbf{6 , 8 1}$ & 3,47 & 2,14 & 4,94 & $\mathbf{4 , 9 4}$ & 1,04 & 0,55 & 1,06 & $\mathbf{1 , 0 6}$ \\
\hline 4 & 8,61 & 7,72 & 10,82 & 10,82 & 4,43 & 2,59 & 8,99 & 8,99 & 1,16 & 1,09 & 1,58 & 1,58 \\
\hline 5 & 9,95 & 8,48 & 11,00 & 11,00 & 3,63 & 2,70 & 6,47 & 6,47 & 1,35 & 1,59 & 2,03 & 2,03 \\
\hline 6 & 10,68 & 7,71 & 12,60 & 12,60 & 6,16 & 3,22 & 9,70 & 9,70 & 1,10 & 1,28 & 1,71 & 1,71 \\
\hline
\end{tabular}

Çizelge 6. Naras Barajı numerik modellerinin analiz sonuçları

\begin{tabular}{|c|c|c|c|c|c|c|c|c|c|c|c|c|}
\hline \multicolumn{9}{|c|}{ Maksimum Kret Deplasman1 (mm) } & \multicolumn{3}{c|}{ Maksimum Kret İvmesi $\left(\mathrm{m} / \mathbf{s n}^{2}\right)$} & \multicolumn{4}{c|}{ Azami Asal Gerilme (MPa) } \\
\hline Kesit & MCE1 & MCE2 & MCE3 & Mak, & MCE1 & MCE2 & MCE3 & Mak, & MCE1 & MCE2 & MCE3 & Mak, \\
\hline 1 & 26,86 & 35,10 & 47,51 & $\mathbf{4 7 , 5 1}$ & 8,25 & 10,17 & 9,92 & $\mathbf{1 0 , 1 7}$ & 2,08 & 3,60 & 4,76 & $\mathbf{4 , 7 6}$ \\
\hline 2 & 25,45 & 38,77 & 53,71 & 53,71 & 11,61 & 11,93 & 16,03 & 16,03 & 2,11 & 4,09 & 5,79 & 5,79 \\
\hline 3 & 25,51 & 35,82 & 48,41 & 48,41 & 8,31 & 10,56 & 9,87 & 10,56 & 2,07 & 3,80 & 5,10 & 5,10 \\
\hline 4 & 28,71 & 38,78 & 50,78 & 50,78 & 10,44 & 10,77 & 15,31 & 15,31 & 2,50 & 4,37 & 5,67 & 5,67 \\
\hline 5 & 28,08 & 39,86 & 54,52 & 54,52 & 11,97 & 11,88 & 15,03 & 15,03 & 3,07 & 5,04 & 6,28 & 6,28 \\
\hline 6 & 32,15 & 41,03 & 56,20 & 56,20 & 14,96 & 15,43 & 19,93 & 19,93 & 3,71 & 5,02 & 6,16 & 6,16 \\
\hline
\end{tabular}

Çizelge 7. Andıraz Barajı numerik modellerinin analiz sonuçları

\begin{tabular}{|c|c|c|c|c|c|c|c|c|c|c|c|c|}
\hline \multicolumn{9}{|c|}{ Maksimum Kret Deplasman1 $(\mathrm{mm})$} & \multicolumn{3}{c|}{ Maksimum Kret İvmesi $\left(\mathrm{m} / \mathrm{sn}^{2}\right)$} & \multicolumn{4}{c|}{ Azami Asal Gerilme (MPa) } \\
\hline Kesit & MCE1 & MCE2 & MCE3 & Mak. & MCE1 & MCE2 & MCE3 & Mak. & MCE1 & MCE2 & MCE3 & Mak. \\
\hline 1 & 74,70 & 83,80 & 82,72 & 83,80 & 14,21 & 19,57 & 14,25 & 19,57 & 3,92 & 3,24 & 3,45 & 3,92 \\
\hline 2 & 79,70 & 84,07 & 84,75 & 84,75 & 16,09 & 22,84 & 16,27 & 22,84 & 3,98 & 3,35 & 3,31 & 3,98 \\
\hline 3 & 71,14 & 77,65 & 75,57 & 77,65 & 13,23 & 17,03 & 11,88 & $\mathbf{1 7 , 0 3}$ & 3,97 & 3,72 & 3,33 & 3,97 \\
\hline 4 & 74,71 & 76,90 & 75,13 & 76,90 & 15,76 & 19,51 & 13,61 & 19,51 & 3,92 & 3,62 & 3,05 & 3,92 \\
\hline 5 & 80,20 & 80,34 & 78,43 & 80,34 & 13,67 & 20,28 & 16,05 & 20,28 & 4,02 & 4,92 & 4,58 & 4,92 \\
\hline 6 & 82,05 & 79,77 & 78,80 & 82,05 & 15,79 & 22,65 & 18,04 & 22,65 & 2,92 & 3,50 & 3,48 & 3,50 \\
\hline
\end{tabular}




\section{SONUÇLAR}

Bu çalışma kapsamında farklı kesit geometrilerinin beton ağırlık barajların sismik performanslarına etkisi incelenmiştir. $\mathrm{Bu}$ nedenle beton ağırlık barajların tasarımı aşamasında kullanılagelen altı farklı kesit geometrisi seçilmiştir. Bu kesitlerin tamamı üç farklı yüksekliğe sahip Gündüzler, Naras ve Andıraz barajlarına uyarlanmıştır. Böylece kati tasarımları ve tasarım aşamasında kullanılan değişkenleri değiştirmeksizin, kesit geometrilerinin barajların sismik taleplerine etkisi incelenmiştir. Seçilen kesitlerin tamamında eşit miktarda malzeme kullanılmıştır. Böylece en ekonomik sonucun hangi kesit seçiminde elde edileceği araştırılmıştır.

Seçilen tüm kesit geometrileri ve baraj yükseklikleri için birer adet numerik model oluşturulmuştur. Numerik modellerde rezervuar etkileşimi için akustik akışkan elemanlar kullanılmıştır. Modeller üç adet deprem senaryosuna tabi tutulmuştur. Elde edilen maksimum kret deplasmanları, kret ivmeleri ve azami asal gerilmeler karşılaştırılmıştır.

Yapılan analiz sonuçlarına göre yüksek zemin rijitliğine sahip barajlar için K3 kesitinin en elverişli sonuçları ürettiği gözlemlenmiştir. Daha az zemin rijitliğine sahip kesitler için $(\mathrm{E}<7500 \mathrm{MPa}) \mathrm{K} 1$ kesitinin az miktarda da olsa daha iyi bir performansa sahip olduğu gözlemlenmiştir.

Gerçekleştirilen analizler sonucunda baraj tasarımında siklıkla kullanılan sistem noktası uygulamasının (K2, K4 ve K6 kesitleri) sanılanın aksine daha ekonomik kesitlere yol açmadığ gözlemlenmiştir.

\section{KAYNAKLAR}

1. Binici, B., Aldemir, A., 2014. Analitik Modellerin Beton Ağırlık Baraj Sismik Davranışını Taklit Etmekteki Verimliliğinin İrdelenmesi, 4. Ulusal Baraj Güvenliği Sempozyumu, 9-11 Ekim 2014, Elazığ.

2. Medina F., Dominguez, J., 1989. Boundary Elements for the Analysis of the Seismic
Response of Dams Including Dam-WaterFoundation Interaction Effects, Engineering Analysis with Boundary Elements 6(3), 152-157.

3. Chopra, A.K., Wang, J., 2008. Analysis and Response of Concrete Arch Dams including Dam-Water-Foundation Rock Interaction to Spatially-Varying Ground Motions, Rapor No. UCB/EERC-2008-03, Earthquake Engineering Research Center, University of California, Berkeley, Kaliforniya.

4. Westergaard, H.M., 1933. Water Pressures on Dams during Earthquakes, Transactions of the American Society of Civil Engineers 98, 418-433.

5. Kuo, J.S., 1982. Fluid Structure Interactions: Added Mass Computations for Incompressible Fluid, Rapor No. UCB/EERC-82/09, Earthquake Engineering Research Center, University of California, Berkeley, Kaliforniya.

6. Chopra, A.K., 1970. Earthquake Response of Concrete Gravity Dams, Journal of Engineering Mechanics ASCE, 96(4), 443-454.

7. Dasgupta, G., Chopra, A.K., 1979. Dynamic Stiffness Matrices for Viscoelastic Half Planes, Journal of Engineering Mechanics ASCE 105(5), 729-745.

8. Fenves, G., Chopra, A.K., 1984. EAGD-84: A Computer Program for Earthquake Response Analysis of Concrete Gravity Dams, Rapor No: UCB/EERC-734, Earthquake Engineering Research Center, University of California, Berkeley, Kaliforniya.

9. Fok, K.L., Hall, J.F., Chopra, A.K., 1986. EACD 3D:A Computer Program for ThreeDimensional Earthquake Analysis of Concrete Dams, Rapor No. UCB/EERC-86/09, Earthquake Engineering Research Center, University of California, Berkeley, Kaliforniya.

10. Tan, H., Chopra, A.K., 1995. Earthquake Analysis and Response of Concrete Arch Dams, Rapor No. UCB/EERC-95/07, Earthquake Engineering Research Center, University of California, Berkeley, Kaliforniya.

11. Chopra, A.K., Wang, J., 2008. Analysis and Response of Concrete Arch Dams Including Dam-water-foundation Rock Interaction to Spatially-varying Ground Motions, Rapor No. UCB/EERC-2008-03, Earthquake Engineering 
Research Center, University of California, Berkeley, Kaliforniya.

12. Fenves, G., Chopra, A.K., 1985. Simplified Earthquake Analysis of Concrete Gravity Dams: Seperate Hydrodynamic and Foundation Interaction Effects, Journal of Engineering Mechanics ASCE 111(6), 715-735.

13. Fenves, G., Chopra, A.K., 1985. Simplified Earthquake Analysis of Concrete Gravity Dams: Combined Hydrodynamic and Foundation Interaction Effects, Journal of Engineering Mechanics ASCE, 111(6), 736-756.

14. Fenves, G., Chopra, A.K., 1987. Simplified Earthquake Analysis of Concrete Gravity Dams, Journal of Structural Engineering ASCE 113(8), 1688-1708.

15. Bouaanani, N., Perrault, C., 2010. Practical Formulas for Frequency Domain Analysis of Earthquake-Induced Dam-Reservoir Interaction, Journal of Engineering Mechanics ASCE 136(1), 107-119.

16. Bhattacharjee S.S., Leger P., 1993. Application of NLFM Models to Predict Cracking in Concrete Gravity Dams, Journal of Structural Engineering ASCE 120(4), 1255-1271.

17. Calayir, Y., Karaton, M., 2005. A Continuum Damage Concrete Model for Earthquake Analysis of Concrete Gravity Dam-Reservoir Systems, Soil Dynamics and Earthquake Engineering 25(11), 857-869.

18. United States Army Corps of Engineering (USACE), 2003. Time History Dynamic Analysis of Concrete Hydraulic Structures, Rapor No: EM 1110-2-6051, Washington, DC.

19. Ulusal Barajlar Kongresi (UBK), 2012. Beton Barajlar Tasarım İlkeleri Rehberi, Devlet $\mathrm{Su}$ İşleri Genel Müdürlüğü, 81.

20. ANSYS Inc., 2016. Basic Analysis Guide for ANSYS 17.1. SAS IP Inc.

21. Gauron, O., Boivin, Y., Ambroise, S., Sanda, A.S., Bernier, C., Paultre, P., Proulx, J., Roberge, M. and Roth, S.N., 2018. ForcedVibration Tests and Numerical Modelling of the Daniel Johnson Multiple-Arch Dam, Journal of Performance of Constructed Facilities 32(2).

22. Sevim, B., Altunisik, A.C., Bayraktar, A., Akköse, M., and Calayir, Y., 2011. Water Length and Height Effects on the Earthquake Behavior of Arch Dam-Reservoir-Foundation
Systems, KSCE Journal of Civil Engineering 15(2), 295-303. 
